\title{
Insulin-like growth factor-I, its binding proteins (IGFBP-1 and IGFBP-3), and growth hormone and breast cancer risk in The Nurses Health Study II
}

\author{
Eva S Schernhammer ${ }^{1,2}$, Jeff M Holly ${ }^{3}$, David J Hunter ${ }^{1,4}$, Michael N Pollak ${ }^{5}$ \\ and Susan E Hankinson ${ }^{1,5}$
}

\author{
${ }^{1}$ Channing Laboratory, Department of Medicine, Brigham and Women's Hospital and Harvard Medical School, 181 Longwood Avenue, Boston, \\ Massachusetts 02115, USA \\ ${ }^{2}$ LBI-ACR VIEnna \& ACR-ITR VIEnna, Vienna, Austria \\ ${ }^{3}$ Department of Surgery, Bristol Royal Infirmary, Bristol, United Kingdom \\ ${ }^{4}$ Department of Epidemiology, Harvard School of Public Health, Boston, Massachusetts, USA \\ ${ }^{5}$ Departments of Medicine and Oncology, McGill University, Montréal, Québec, Canada H3T 1E2
}

(Requests for offprints should be addressed to E S Schernhammer; Email: eva.schernhammer@channing.harvard.edu)

\begin{abstract}
Earlier data suggest that the relationship between circulating insulin-like growth factor I (IGF-I) levels and breast cancer risk differs according to menopausal status. We evaluated the association between IGF levels as well as the primary regulator of IGF-I production, growth hormone (GH), and breast cancer risk in the Nurses' Health Study II (NHS II) cohort, a large cohort of primarily premenopausal women. We conducted a case-control study nested within the prospective NHS II cohort. Plasma concentrations of IGF-I, IGF binding protein (IGFBP)-3, IGFBP-1, and GH were measured in blood samples collected between 1996 and 1999. Totally 317 women were identified who had a diagnosis of invasive or in situ breast cancer between the date of blood collection and June $12003 ; 75 \%$ of these women were premenopausal at blood collection. To each of the 317 women, two controls were age-matched for a total of 634 controls. We used conditional logistic regression models to estimate the relative risk of breast cancer. Overall, plasma IGF-I, IGFBP-1, IGFBP-3, and GH levels were not associated with breast cancer risk (relative risks, top vs bottom quartile; IGF-I, 0.98, 95\% confidence interval $(\mathrm{Cl}), 0.69-1.39$; IGFBP-1, 0.95, 95\% Cl, 0.63-1.41; IGFBP-3, 1.10, 95\% Cl, 0.78-1.54; GH, $1.09,95 \% \mathrm{Cl}$, $0.82-1.46)$. These risks were similar for premenopausal women of age 45 years or less. Further adjustment for additional breast cancer risk factors did not change these estimates. In conclusion, circulating IGF-I, IGFBP-1, IGFBP-3, and GH levels appear to have no important association with breast cancer risk in a large cohort of premenopausal women.
\end{abstract}

Endocrine-Related Cancer (2006) 13 583-592

\section{Introduction}

Insulin-like growth factor I (IGF-I) is a peptide hormone that, with IGF-II, IGF binding proteins (IGFBPs), and cell-surface receptors, is integral to the regulation of cell survival and death. IGF-I appears to be associated with breast cancer risk, particularly among premenopausal women (Hankinson \& Schernhammer 2003). However, results from observational studies are not entirely consistent
(Kaaks et al. 2002, Hankinson \& Schernhammer 2003), and uncertainty exists about the true association between IGF-I and breast cancer risk. IGF-I production in the liver, the primary source of circulating IGF-I (Jones \& Clemmons 1995), is regulated primarily by human growth hormone $(\mathrm{GH})$, which is produced by the pituitary gland. To our knowledge, no study has evaluated the association between circulating $\mathrm{GH}$ levels and breast cancer risk. IGFBP-3, along with IGFBP-1, are two of six 
currently identified IGFBPs that, by binding IGF peptides, prolong their half-lives and may alter the interaction of IGFs with their cell surface receptors (Shimasaki \& Ling 1991).

Using a nested case-control design within the large, prospective Nurses' Health Study II (NHS II) cohort of primarily premenopausal women, we investigated an association between plasma IGF-I, its binding proteins IGFBP-1 and IGFBP-3, and $\mathrm{GH}$ and breast cancer risk. C-peptide was measured for the purpose of conducting analyses stratified by $\mathrm{C}$-peptide as an index of insulin resistance.

\section{Materials and methods}

\section{Study population}

The NHS II is a prospective cohort study that started in 1989 when 116671 registered female US nurses aged 25 to 42 from 14 US states were enrolled. The NHS II was designed akin to the Nurses' Health Study (NHS), an earlier, independent cohort study of similar size that was initiated in 1976 (Colditz \& Hankinson 2005). The baseline questionnaire sought hormone use, reproductive history, current medication, history of disease, and a number of life-style factors. Since then, women have been followed biennially by mailed questionnaires, ascertaining any diagnosis of breast cancer, including date of diagnosis. For women who reported a diagnosis of breast cancer, we requested permission to review relevant medical records, all of which were reviewed by trained physicians. For deceased participants, we sought permission from next-of-kin to review these records. More than $99 \%$ of reported breast cancers were confirmed by medical record review. Further details of the cohort have been published (Rockhill et al. 1998).

Women who had not previously reported a diagnosis of cancer were eligible for sample collections; in total, 29611 women in the NHS II cohort participated in our blood collection study from 1996 to 1999 . We provided blood collection kits and advised each participant to have blood samples drawn by a local laboratory or colleague. First samples were drawn in the follicular phase of the menstrual cycle; second samples were collected in the luteal phase. Samples were returned to our laboratory via overnight courier, with a frozen water sample to keep them cool. To time samples within the menstrual cycle, a postcard was included in the blood kit on which nurses indicated the first day of their next menstrual cycle after blood collection. Of the 29611 participants, 18521 provided detailed information on the onset of their menstrual cycle, and 11090 more women provided single, untimed blood samples. A brief questionnaire was included with the blood kit, asking the specific date and time when blood samples were drawn, the first day of the nurse's current menstrual cycle, the number of hours since she had last eaten, her current weight and medication use, and any changes in her menstrual cycle characteristics. For women who gave both follicular and luteal samples, we used luteal samples in this study, because cyclic variations of IGF are only modest (Juul et al. 1997, Helle et al. 1998).

Cases in this analysis are women with no cancer diagnosis (with the exception of non-melanoma skin cancer) prior to blood collection and with breast cancer diagnosis between the date of blood collection and June 1 2003. In all, 317 cases of breast cancer ( $n=80$ in situ) were confirmed by medical record review (two controls selected before 2001 became cases in 2003, we kept them as controls only, leaving 317 cases of the initial 319 cases). Although the 317 cases included 11 women whose pathology reports have not yet been obtained, we based our analyses on the total, because the accuracy of self-reporting was extremely high (Rockhill et al. 1998). Estrogen receptor (ER) status was also abstracted from medical records (168 of the invasive cancers were $\mathrm{ER}+$ ). To each case, we matched two controls on year of birth, menopausal status at blood draw and at diagnosis of breast cancer (postmenopausal vs premenopausal vs unknown), time of day and month of blood draw, fasting status at blood draw ( $\geq 8 \mathrm{~h}$ since a meal vs not), luteal day (number of days before start of next cycle), and ethnicity (African-American, Asian, Hispanic, Southern European/Scandinavian/other Caucasian, and other). In sum, a total of 317 cases and 634 controls formed the study population for the current analyses. The study was approved by the Committee on the Use of Human Subjects in Research at the Brigham and Women's Hospital and the Harvard School of Public Health.

We defined menopausal status at the time of blood collection in our main analyses. Women who provided a timed sample were considered to be premenopausal. Women providing a random sample were considered premenopausal if they (a) reported that periods had not ceased or (b) had a hysterectomy but had at least one ovary remaining and were $\leq 45$ (for nonsmokers) or $\leq 47$ (for smokers) years of age - at these ages fewer than $10 \%$ of the cohort had had a natural menopause. Women were 
considered postmenopausal if they (a) reported that natural menstrual periods had ceased permanently, (b) had a bilateral oophorectomy, or (c) had a hysterectomy but had at least one ovary remaining, and were at least 56 (for nonsmokers) or 54 (for smokers) years of age - by these ages natural menopause had occurred in $90 \%$ of the cohort. All other women were considered to be of unknown menopausal status $(<1 \%)$. Of the 239 women who were premenopausal at blood collection, all but 14 were still premenopausal at diagnosis.

For IGFBP-1 analyses, only fasting blood samples were used. Total IGF-I, IGFBP-1, IGFBP-3, GH, and C-peptide levels were assayed by ELISA after acid extraction, using reagents from Diagnostic Systems Laboratory (DSL, Webster, TX, USA). To test whether the IGFBP-3 assay itself could account for variability in the results of associations between IGFBP-3 and breast cancer risk, IGFBP-3 levels for a portion of the data set (cases up to 2001 and their matched controls) were also assayed in Professor Holly's laboratory in Bristol, UK by a previously validated RIA, using an in-house polyclonal antibody and calibrated against recombinant human glycosylated IGFBP-3 (Cheetham et al. 1998). For a comparison of the ELISA results with this RIA see Table 2. As they were highly correlated, we used results obtained from the ELISA assays for IGFBP-3 in our final analyses. For that data set we also had IGF-I and IGFBP-3 levels assayed with an alternative ELISA, using the chemiluminescent immunoassay system (Immulate, Diagnostic Products Coorporation, CA, USA). When plotting the differences against the averages of the two measurements (ELISA versus alternative ELISA), the two different methods demonstrated good agreement between the two assays (Spearman $r=0.94$ ) for IGF-I. For IGFBP-3, the plot suggested that the variation of at least one ELISA measurement depended on the magnitude of the measurements (Spearman $r=0.90$ ). We therefore compared the standard DSL ELISA with IGFBP-3 measurements obtained by RIA, which is currently considered the gold standard for measuring IGFBP-3. The BlandAltman plot (Bland \& Altman, 1986) demonstrated good agreement between these two measurements. Moreover, IGFBP-3 RIA measurements were highly correlated with those obtained by standard ELISA (see Table 2) and will therefore not be used for this report. All samples were masked to case or control status. Masked split specimens included within each batch were used to calculate the coefficient of variation within batches; for IGF-I these were $6.8 \%$, for IGFBP-3 $4.2 \%$, for IGFBP-1 $1.6 \%$, for $\mathrm{GH} 11.3 \%$, and for C-peptide $4.3 \%$.

Evidence that a single plasma measurement of IGF-I and IGFBP-3 reflects longer term circulating levels is limited, but correlations ranged from 0.94 to 0.97 for samples measured over 8 weeks (Goodman-Gruen \& Barrett-Connor 1997), 0.81 for IGF-I and 0.60 for IGFBP-3 measured over 1 year (Muti et al. 2002), suggesting that a single measure reflects average levels over at least a 1year period. We also found good reproducibility of IGF-I and IGFBP-3 in NHS II (Missmer et al. 2006) over time (over 3 years, premenopausal women only, $r=0.83$ for IGF-I, and intra-class correlation $($ ICC $)=0.76$ for IGFBP-3). This level of reproducibility is similar for other biological variables, such as blood pressure and serum cholesterol measurements (ICC, 0.6-0.8 over several years), parameters considered reasonably well measured and consistent predictors of disease in epidemiological studies. In the NHS, we had conducted similar analyses for $\mathrm{GH}$, with reproducibility over 3 years $(\mathrm{ICC}=0.44)$.

\section{Statistical analyses}

We identified statistical outliers based on the generalized extreme studentized deviate (ESD) many-outlier detection approach (Rosner 1983); two women with improbable IGFBP-1 concentrations were identified as outliers and excluded from analyses that included IGFBP-1. Overall, we had fewer women with IGFBP-1 levels (191 cases and 378 controls) available for our analyses because the set of women who had provided fasting blood samples was smaller. To test for differences in hormone levels between cases and controls, we used mixed-effects regression models for clustered data to adjust for possible confounding due to the matching factors and for any residual correlation between case and control subjects within the matched set (Zeger et al. 1988). Quartiles of IGF levels were defined on the basis of plasma levels of all controls for the overall analyses and of IGF levels of all premenopausal controls for the analyses restricted to various subgroups of premenopausal women. In sub-analyses, to better classify individuals with respect to their individual insulin levels, we stratified by the plasma C-peptide median (using C-peptide as a marker of insulin production). As more than $30 \%$ of all $\mathrm{GH}$ values, which we analyzed in two batches, were below the detection limit of the $\mathrm{GH}$ assay $(0.14 \mathrm{ng} / \mathrm{ml}$ and $0.21 \mathrm{ng} / \mathrm{ml}$ 
respectively), all women with values $\leq 0.21 \mathrm{ng} / \mathrm{ml}$ constituted the reference group; for the remaining women tertiles were defined according to plasma levels of all controls, for a total of four categories.

To estimate the relative risks (odds ratios, ORs) and $95 \%$ confidence intervals (95\% CIs), we used conditional logistic regression models, adjusting for the matching factors. In sub-analyses, we additionally adjusted for other breast cancer risk factors (age at menarche (less than 12 years, 12 years, 13 years, and $14+$ years), parity (0, 1-2 births, 3-4 births, more than 4 births), age at birth of first child (0, less than 25 years, 25-29 years, 30+ years), family history of breast cancer (in mother or sister, yes $/$ no), and body mass index (BMI) $\left(<21 \mathrm{~kg} / \mathrm{m}^{2}, \quad 21-22.9 \mathrm{~kg} / \mathrm{m}^{2}, \quad 23-24.9 \mathrm{~kg} / \mathrm{m}^{2}, \quad 25-\right.$ $28.9 \mathrm{~kg} / \mathrm{m}^{2}$, and $\left.29+\mathrm{kg} / \mathrm{m}^{2}\right)$ ). We tested for trends by calculating the Wald statistics for a continuous distribution of IGF values, using the square-root of IGF-I because of its skewed distribution. For analyses stratifying on number of years diagnosed after blood collection, we also estimated ORs for continuous measures of IGF-I and IGFBP-3 transformed on the $\log _{2}$ scale $\left[\log _{2} x=\log (x) / \log (2)\right]$.

In contrast to our previous publication (Hankinson et al. 1998), we included in situ breast cancer cases in the current analyses, since our results, which overall are similar to our recent update in the NHS (Schernhammer et al. 2005) remained essentially unchanged after exclusion of in situ cases (but not their controls).

\section{Results}

Table 1 shows baseline characteristics of the 317 cases and 634 controls, by subgroups. The mean time between blood collection and diagnosis was 31 months (S.D. 20) with a range of 1-88 months.
Table 1 Baseline characteristics

\begin{tabular}{|c|c|c|}
\hline & Cases & Controls \\
\hline All women & $n=317$ & $n=634$ \\
\hline$\ddagger$ Age (mean (S.D.)) & $45.3(4.3)$ & $45.1(4.3)$ \\
\hline Age at menarche (mean (S.D.)) & $12.4(1.4)$ & $12.4(1.4)$ \\
\hline Parity* (mean (S.D.)) & $2.2(0.8)$ & $2.3(1.0)$ \\
\hline Family history of breast cancer (\%) & 16.4 & 10.4 \\
\hline Oral contraceptive use $\dagger(\%)$ & 2.8 & 2.2 \\
\hline BMI (mean (S.D.)) & $25.3(5.3)$ & $25.7(6.0)$ \\
\hline Premenopausal women & $n=239$ & \\
\hline$\ddagger$ Age (me & $44.1(4.0)$ & $43.8(3.9)$ \\
\hline Age at menarche (mean (S.D.)) & $12.5(1.4)$ & $12.4(1.4)$ \\
\hline Parity* (mean (S.D.)) & $2.1(0.8)$ & $2.3(1.0)$ \\
\hline Family history of breast cancer (\%) & 15.5 & 9.8 \\
\hline Oral contraceptive use $\dagger(\%)$ & 2.9 & 2.3 \\
\hline BMI (mean (S.D.)) & $24.9(5.0)$ & $25.1(5.4)$ \\
\hline Premenopausal women & $n=129$ & $n=275$ \\
\hline$\ddagger$ Age (mean (S.D.)) & $41.1(2.8)$ & $41.1(2.8)$ \\
\hline Age at menarche (mean (S.D.)) & $12.4(1.5)$ & $12.4(1.4)$ \\
\hline Parity* (mean (S.D.)) & $2.1(0.8)$ & $2.3(0.9)$ \\
\hline Family history of breast cancer (\%) & 13.2 & 8.0 \\
\hline Oral contraceptive use $\dagger(\%)$ & 3.9 & 1.8 \\
\hline BMI (mean (S.D.)) & $24.8(5.7)$ & $24.7(5.0)$ \\
\hline
\end{tabular}

*Among parous women only. $\dagger$ Current (1997). $\ddagger$ Age at blood draw.

Total IGF-I and IGFBP-3 were positively correlated with each other, whereas IGF-I and age were inversely correlated, whereas height was not correlated with either IGF-I or GH (Table 2). IGFBP-1 was weakly and inversely correlated with both IGF-I and IGFBP-3 and weakly positively associated with $\mathrm{GH}$. The correlation between $\mathrm{GH}$ and IGF-I, finally, was $r=-0.09(P=0.03)$. The two measures for IGF-I and IGFBP-3 that we had available for our analyses in a portion of the data set (ELISA versus alternative ELISA) were well correlated with each other (IGF-I: Spearman $r=0.94, P<0.001$; IGFBP-3: $r=0.87, P<0.001)$.

Table 2 GH and IGFs correlation matrix, all women combined (controls only)

\begin{tabular}{|c|c|c|c|c|c|c|c|}
\hline & \multicolumn{7}{|c|}{$\begin{array}{l}\text { Spearman correlation coefficient }(r) \text { between the untransformed continuous measures of GH } \\
\text { and various IGFs }\end{array}$} \\
\hline & $\mathrm{GH}$ & IGF-I & IGFBP-1 & IGFBP-3 (ELISA) & IGFBP-3 (RIA) & Age & Height \\
\hline $\mathrm{GH}$ & 1.0 & -0.09 & 0.16 & -0.02 & -0.06 & -0.0006 & -0.01 \\
\hline IGF-I & & 1.0 & -0.16 & 0.51 & 0.39 & -0.25 & 0.05 \\
\hline IGFBP-1 & & & 1.0 & -0.16 & -0.17 & 0.19 & -0.03 \\
\hline IGFBP-3 (ELISA) & & & & 1.0 & 0.85 & -0.13 & 0.01 \\
\hline IGFBP-3 (RIA) & & & & & 1.0 & -0.02 & 0.01 \\
\hline Age & & & & & & 1.0 & -0.06 \\
\hline Height & & & & & & & 1.0 \\
\hline
\end{tabular}


Table 3 Plasma GH, IGF-I, IGFBP-1 and IGFBP-3 concentrations by case or control status

\begin{tabular}{|c|c|c|c|c|c|}
\hline & \multicolumn{2}{|r|}{ Cases } & \multicolumn{2}{|c|}{ Controls } & \multirow[b]{2}{*}{$P \dagger$} \\
\hline & $n$ & Median (range* ${ }^{*}$ & $n$ & Median (range* ${ }^{*}$ & \\
\hline \multicolumn{6}{|l|}{ IGF-I (ng/ml) } \\
\hline All cases or controls & 317 & $230(153-346)$ & 634 & $239(135-341)$ & 0.83 \\
\hline Premenopausal & 239 & 242 (164-352) & 478 & $249(150-350)$ & 0.85 \\
\hline Premenopausal, age $\leq 45$ & 129 & 260 (167-367) & 275 & $258(151-350)$ & 0.40 \\
\hline \multicolumn{6}{|l|}{ IGFBP-3 (ng/ml) (ELISA) } \\
\hline All cases or controls & 317 & $4864(4068-5967)$ & 634 & $4881(4000-5911)$ & 0.72 \\
\hline Premenopausal & 239 & $4918(4137-5967)$ & 478 & $4936(4000-6030)$ & 0.81 \\
\hline Premenopausal, age $\leq 45$ & 129 & 5139 (4267-6002) & 275 & 5021 (4092-5929) & 0.27 \\
\hline \multicolumn{6}{|l|}{ IGFBP-1 (ng/ml) } \\
\hline All cases or controls & 191 & $38.7(10.6-73.1)$ & 378 & $35.3(10.3-75.8)$ & 0.55 \\
\hline Premenopausal & 129 & $36.4(11.1-66.8)$ & 255 & 33.6 (11.4-67.9) & 0.61 \\
\hline \multicolumn{6}{|l|}{$\mathrm{GH}(\mathrm{ng} / \mathrm{ml})$} \\
\hline All cases or controls & 317 & $0.24(0.14-5.27)$ & 634 & $0.25(0.14-4.03)$ & 0.45 \\
\hline Premenopausal & 239 & $0.23(0.14-5.39)$ & 478 & $0.24(0.14-4.10)$ & 0.47 \\
\hline Premenopausal, age $\leq 45$ & 129 & $0.23(0.14-5.39)$ & 275 & $0.21(0.14-4.03)$ & 0.43 \\
\hline
\end{tabular}

* Range of plasma values, 10th to 90th percentile.

$\dagger P$-values for comparison of mean natural IGF plasma levels between cases and controls, based on mixed-effects regression models with adjustment for the matching variables.

Neither total IGF-I, nor IGFBP-1, IGFBP-3, or GH levels varied significantly between cases and controls in the whole cohort, nor did they vary among premenopausal women or premenopausal women of age 45 years or less (Table 3 ).

Throughout the study population, circulating IGF-I levels were not associated with breast cancer risk; nor did additional adjustment for IGFBP-3 or breast cancer risk factors such as BMI and family history of breast cancer alter these estimates (Table 4). The risks remained essentially unchanged after the exclusion of in situ breast cancer cases (relative risk (RR), top vs bottom quartile, $1.03 ; 95 \% \mathrm{CI}$, $0.69-1.54)$, as they did after exclusion of current or recent users of either hormone-replacement therapy or oral contraceptives (OC) (RR, top vs bottom quartile, $1.01 ; 95 \%$ and $5 \% \mathrm{CI}, 0.68-1.51)$. Moreover, there was no marked difference in risks stratified along the median (34 months) of duration of OC use, as assessed in 1997 ( $\geq 34$ months of OC use: RR, top vs bottom quartile, $0.81 ; 95 \% \mathrm{CI}, \quad 0.51-1.30 ;<34$ months of OC use: RR, top vs bottom quartile, 1.20; 95\% CI, 0.62-2.32).

IGFBP-3 and IGFBP-1 were similarly not associated with breast cancer risk and further adjustment for IGF-I did not alter these estimates (Table 4). For $\mathrm{GH}$, the relative risk, comparing top and bottom quartiles was 1.09 (95\% CI, 0.82-1.46).
In sub-analyses, when we restricted our data set to women who were premenopausal at blood collection (Table 4) or to premenopausal women of age 45 years or less at blood collection, the lack of an association between IGF-I and breast cancer risk remained essentially unchanged. Furthermore, among invasive cases, we observed no association of plasma IGF levels stratified by hormone receptor status of the tumor: IGF-I was not associated with either ERnegative (RR, top vs bottom tertile, $1.25,95 \% \mathrm{CI}$, 0.49 to 3.18 ) or ER-positive tumors (RR, top vs bottom tertile, $1.14,95 \% \mathrm{CI}, 0.70$ to 1.85 ) among women who were premenopausal at blood collection. A previous report (Bruning et al. 1995) indicated decreased IGFBP-3 levels in early-stage premenopausal breast cancer. We therefore evaluated the association between circulating IGFBP-3 levels and breast cancer risk in smaller tumors only (tumor size at diagnosis $\leq 2 \mathrm{~cm}$ ), but could not confirm those findings (RR top vs bottom IGFBP-3 quartile, $1.08,95 \%$ CI, 0.66 to 1.77 ).

To further explore differences in the relationship between IGF-I and IGFBP-3 and breast cancer risk depending on the interval between blood donation and tumor diagnosis, we stratified on the number of years since blood collection and evaluated the RR associated with a doubling of levels (i.e. a unit increase on the $\log _{2}$ scale). The risks 
E S Schernhammer et al.: IGF-I, IGFBP-1, IGFBP-3, GH levels and breast cancer risk

Table 4 Relative risk $\ddagger$ of breast cancer by plasma IGF and GH quartiles, 1996-2003 for all women combined

\begin{tabular}{|c|c|c|c|c|c|}
\hline & Q1 & Q2 & Q3 & Q4 & $P$ for trend \\
\hline \multicolumn{6}{|l|}{ IGF-I } \\
\hline Cases/controls & $78 / 157$ & $90 / 160$ & $70 / 159$ & $79 / 158$ & \\
\hline IGF-I & 1.0 & $1.09(0.80-1.47)$ & $0.92(0.67-1.27)$ & $1.00(0.73-1.37)$ & 0.77 \\
\hline IGF-I $\dagger$ & 1.0 & $1.07(0.79-1.46)$ & $0.91(0.65-1.27)$ & $0.98(0.69-1.39)$ & 0.77 \\
\hline $\mid G F-19$ & 1.0 & $1.14(0.83-1.56)$ & $0.92(0.65-1.29)$ & $0.96(0.67-1.37)$ & 0.91 \\
\hline \multicolumn{6}{|l|}{ IGFBP-3 (ELISA) } \\
\hline IGFBP-3 & 1.0 & $1.04(0.76-1.41)$ & $0.92(0.67-1.27)$ & $1.07(0.79-1.45)$ & 0.76 \\
\hline IGFBP-3† & 1.0 & $1.05(0.77-1.45)$ & $0.94(0.67-1.32)$ & $1.10(0.78-1.54)$ & 0.64 \\
\hline \multicolumn{6}{|l|}{ IGFBP-1 } \\
\hline IGFBP-1† & 1.0 & $0.73(0.47-1.14)$ & $1.16(0.80-1.69)$ & $0.95(0.63-1.41)$ & 0.50 \\
\hline \multicolumn{6}{|l|}{$\mathrm{GH}$} \\
\hline Cases/controls & $145 / 284$ & $58 / 115$ & $46 / 119$ & $68 / 116$ & \\
\hline $\mathrm{GH} \ddagger$ & 1.0 & $0.99(0.73-1.35)$ & $0.83(0.59-1.15)$ & $1.09(0.82-1.46)$ & 0.51 \\
\hline \multicolumn{6}{|c|}{ Premenopausal women } \\
\hline \multicolumn{6}{|l|}{ IGF-I } \\
\hline Cases/controls & $47 / 94$ & $69 / 119$ & $53 / 130$ & $70 / 135$ & \\
\hline IGF-I & 1.0 & $1.10(0.76-1.60)$ & $0.87(0.59-1.29)$ & $1.02(0.71-1.48)$ & 0.87 \\
\hline IGF-I $\dagger$ & 1.0 & $1.07(0.74-1.56)$ & $0.83(0.55-1.25)$ & $0.94(0.63-1.42)$ & 0.57 \\
\hline IGF-1ब & 1.0 & $1.13(0.77-1.65)$ & $0.83(0.55-1.25)$ & $0.92(0.61-1.41)$ & 0.48 \\
\hline \multicolumn{6}{|l|}{ IGFBP-3 (ELISA) } \\
\hline IGFBP-3 & 1.0 & $1.07(0.74-1.54)$ & $0.98(0.67-1.42)$ & $1.17(0.82-1.66)$ & 0.90 \\
\hline IGFBP-3† & 1.0 & $1.09(0.75-1.58)$ & $1.02(0.68-1.51)$ & $1.23(0.83-1.82)$ & 0.79 \\
\hline \multicolumn{6}{|l|}{ IGFBP-1 } \\
\hline IGFBP-1 1 & 1.0 & $0.81(0.48-1.37)$ & $1.07(0.66-1.73)$ & $0.68(0.37-1.24)$ & 0.60 \\
\hline \multicolumn{6}{|l|}{$\mathrm{GH}$} \\
\hline Cases/controls & $112 / 223$ & $41 / 76$ & $33 / 89$ & $53 / 90$ & \\
\hline $\mathrm{GH} \ddagger$ & 1.0 & $1.05(0.73-1.50)$ & $0.81(0.55-1.19)$ & $1.11(0.80-1.54)$ & 0.50 \\
\hline \multicolumn{6}{|c|}{ Premenopausal women age $\leq 45$} \\
\hline \multicolumn{6}{|l|}{ IGF-I } \\
\hline Cases/controls & $21 / 45$ & $25 / 57$ & $34 / 87$ & $49 / 86$ & \\
\hline IGF-I & 1.0 & $0.96(0.54-1.71)$ & $0.88(0.51-1.52)$ & $1.14(0.68-1.90)$ & 0.70 \\
\hline IGF-I $\dagger$ & 1.0 & $0.89(0.49-1.60)$ & $0.80(0.45-1.40)$ & $0.97(0.55-1.70)$ & 0.85 \\
\hline IGF-19 & 1.0 & $0.85(0.46-1.56)$ & $0.76(0.43-1.37)$ & $0.90(0.51-1.62)$ & 0.85 \\
\hline \multicolumn{6}{|l|}{ IGFBP-3 (ELISA) } \\
\hline IGFBP-3 & 1.0 & $1.25(0.71-2.19)$ & $1.30(0.76-2.22)$ & $1.49(0.88-2.51)$ & 0.36 \\
\hline IGFBP-3† & 1.0 & $1.27(0.72-2.25)$ & $1.31(0.75-2.27)$ & $1.49(0.84-2.65)$ & 0.49 \\
\hline \multicolumn{6}{|l|}{$\mathrm{GH}$} \\
\hline Cases/controls & $60 / 137$ & $25 / 36$ & $15 / 51$ & $29 / 51$ & \\
\hline $\mathrm{GH} \ddagger$ & 1.0 & $1.35(0.84-2.15)$ & $0.75(0.42-1.32)$ & $1.19(0.76-1.85)$ & 0.54 \\
\hline
\end{tabular}

$\dagger$ Relative risks were, in addition to matching variables, further adjusted for plasma IGF-I or IGFBP-3.

- Relative risks were, in addition to matching variables and IGF-I or IGFBP-3, further adjusted for the following breast cancer risk factors: age at menarche (less than 12 years, 12 years, 13 years, and 14+ years), parity (0,1-2 births, 3-4 births, more than 4 births), age at birth of first child (0, less than 25 years, $25-29$ years, $30+$ years), family history of breast cancer (yes $/ \mathrm{no})$, and BMl $\left(<21 \mathrm{~kg} / \mathrm{m}^{2}, 21-22.9 \mathrm{~kg} / \mathrm{m}^{2}\right.$, $23-24.9 \mathrm{~kg} / \mathrm{m}^{2}, 25-28.9 \mathrm{~kg} / \mathrm{m}^{2}$, and $\left.29+\mathrm{kg} / \mathrm{m}^{2}\right)$.

$\ddagger$ Analyses based on conditional logistic regression models.

were independent of time since collection (women with a diagnosis of breast cancer within 2 years following blood collection: IGF-I, RR, 0.99, 95\% CI, 0.69-1.43; IGFBP-3, RR, 1.09, 95\% CI, 0.492.42; women with a diagnosis of breast cancer more than two years after blood collection: IGF-I, RR, 1.06, 95\% CI, 0.74-1.53; IGFBP-3, RR, 1.24, 95\% CI, 0.56-2.74).

Finally, to explore the possible influence of insulin resistance on the associations (using C-peptide as a 
marker of insulin production), we stratified our data by the median C-peptide level. We would expect women with lower C-peptide levels (i.e. not resistant to the effects of higher IGF-I levels) to be at higher risk of breast cancer due to IGF-I than those with higher C-peptide levels. However, we were unable to confirm this hypothesis: in unconditional logistic regression models (adjusting for the matching factors and additional breast cancer risk factors), we observed an RR of 1.32 (95\% CI, 0.57-3.05) associated with the top quartile of IGF-I (compared with the bottom quartile of IGF-I) in the stratum of women with C-peptide levels above the median compared with 0.83 (95\% CI, 0.35-1.93) in women with C-peptide levels below the median.

\section{Discussion}

In a matched, nested case-control study of breast cancer, we found no association between IGF levels and premenopausal breast cancer risk and no association between plasma GH, IGFBP-1, or IGFBP-3 and breast cancer risk.

Persuasive basic science suggests that the proliferative effects of IGF-I influence both normal and transformed breast epithelial cells (Bates et al. 1995, Yang et al. 1996, Ng et al. 1997) and increase the frequency of breast tumors (Medical Intelligence Unit 2003). The expression of IGFBP-3 in many tissues, on the other hand, suggests that it locally modulates the action of IGF peptides. IGFBP-3 may have other, not yet fully understood, physiological roles. Finally, IGFBP-1, another binding protein, also regulates IGF actions (Medical Intelligence Unit 2003). GH, a hormone produced by the pituitary gland, is the primary regulator of hepatic IGF-I production, which, in turn, is the main source of circulating IGF-I (Jones \& Clemmons 1995).

To date, seven prospective analyses have evaluated associations between IGFs and premenopausal breast cancer risk (Hankinson et al. 1998, Toniolo et al. 2000, Kaaks et al. 2002, Krajcik et al. 2002, Muti et al. 2002, Allen et al. 2005, Rinaldi 2005, Schernhammer et al. 2005). Three nested casecontrol studies among premenopausal and postmenopausal women (Toniolo et al. 2000, Krajcik et al. 2002, Muti et al. 2002, Allen et al. 2005) reported a positive association among premenopausal women. In all three, women with high premenopausal levels of IGF-I had a two- to threefold higher risk of breast cancer, while levels in postmenopausal women were unrelated to risk. Recently published extensions of two of these studies found generally similar results (Rinaldi et al. 2005, Schernhammer et al. 2005). In the largest prior prospective evaluation, data were analyzed from a total of 513 incident breast cancer cases and 987 matched controls, a study nested within two large Swedish cohorts (Kaaks et al. 2002). In contrast to the previous studies, the authors observed no noteworthy associations between plasma IGF levels and breast cancer risk among the 116 premenopausal cases and 330 controls (RR, top vs bottom quartile, $0.6,95 \% \mathrm{CI}, 0.3-1.4)$.

Many studies have investigated the relationship between IGFBP-3 and breast cancer risk. The first of the prospective studies published (Toniolo et al. 2000) noted no significant association for IGFBP-3 among either premenopausal or postmenopausal women. Subsequent cohort studies tended to confirm these findings in premenopausal women, with one exception (Muti et al. 2002), and with more inconsistent reports about the association between circulating IGFBP-3 levels and breast cancer risk among postmenopausal women (Kaaks et al. 2002, Keinan-Boker et al. 2002, Krajcik et al. 2002, Muti et al. 2002).

A few prospective studies also examined associations of IGFBP-1 with breast cancer risk (Kaaks et al. 2002, Krajcik et al. 2002, Schernhammer et al. 2005). All three studies, including our own results from the NHS cohort (Schernhammer et al. 2005), report no association of IGFBP-1 with breast cancer. The three retrospective studies that examined the associations of IGFBP-1 with breast cancer (Favoni et al. 1995, Del Giudice et al. 1998, Goodwin et al. 2002) overall confirm this absence of an important association. To our knowledge, no previous study has evaluated associations of circulating GH levels with breast cancer risk. Previous studies report strong correlations between $\mathrm{GH}$ and IGF-I, particularly in utero $(r=0.42)$ (Chellakooty et al. 2004). Although the reproducibility of $\mathrm{GH}$ appeared to be reasonable in a comparable data set (the NHS, ICC $=0.44$ ), it was still lower than for IGF-I, which may explain the lack of correlation between GH and IGF-I and between circulating $\mathrm{GH}$ levels and breast cancer risk in this study. Moreover, the quickly changing, pulsatile excretion pattern of $\mathrm{GH}$ makes this hormone difficult to measure, and our results must, therefore, be interpreted with great caution.

More recent studies, including our own update (Schernhammer et al. 2005) of previously published data (Hankinson et al. 1998) and updated data from the New York University Women's Health Study 
cohort (Rinaldi et al. 2005), have observed weaker associations between circulating IGF-I levels and breast cancer risk among premenopausal women than initially reported. Similarly, the findings from our current study of primarily premenopausal women show no association at all. What could account for these puzzling differences? The most likely explanations are either methodological issues or secular changes over time, particularly if linked to a woman's hormonal status, given the lack of similar changes in results over time with colon cancer (Giovannucci et al. 2000, Wei et al. 2005).

With our two data sets (NHS and NHS II) at hand, we therefore considered methodological issues comparing the two cohorts, and evaluated a variety of hormone-related breast cancer risk factors that could account for the discrepancies, potentially reflecting a secular change in lifestyle factors.

First, blood sampling, transportation, and storage methods are identical between the two cohorts. Technical issues related to the assays used for IGF-I measurements, although they admittedly exist (Rinaldi et al. 2005), also appear to be an unlikely explanation, considering the high correlation between two different ELISA assays for IGF-I in our study. In addition, given that the positive association between IGF-I and colon cancer risk in the NHS cohort remained in a more recent update (Wei et al. 2005), whatever affects the changes seen in risk may only relate to breast cancer. We therefore compared some of the baseline breast cancer risk factors between the two cohorts but were unable to detect important differences. For example, the average body mass index of premenopausal women was comparable between cohorts (mean, NHS: cases 25.4; controls 25.7; NHS II: cases 24.9; controls 25.1), as were IGF-I and IGFBP-3 ranges, although levels of both IGF-I and IGFBP-3 were slightly higher in the NHS II (as expected in this younger group) than in the NHS. Correlations between IGF-I and IGFBP-3 (NHS: $r=0.57$ vs NHS II; $r=0.51$ ) and IGF-I and age (NHS: $r=-0.33$ vs NHS II, $r=-0.25$ ) were also comparable.

With no obvious explanation at hand, there is room for speculation. One obvious hypothesis to explain the discrepancies in IGF studies conducted over the past decade is that circulating IGF-I levels, as measured in epidemiological studies, do not accurately reflect long-term IGF-I levels. However, while no studies have reported the ICC of IGF-I measures taken many years apart, studies have shown a reasonable ICC for shorter intervals.
Also, there is no reason to believe that the misclassification resulting from the use of a single IGF measure would vary substantially between studies. Alternatively, one could hypothesize that, in the past, there were environmental interactions with IGF levels that vanished over time. However, all studies on IGF-I and breast cancer risk collected their blood samples at various time points, and it would be hard (if not impossible) to pin such an event to a certain period. Another theory might support the relevance of much earlier exposures to IGF-I (i.e. in adolescence); it is conceivable that, while adult levels (particularly when measured before menopause) may have reflected adolescence levels in the past, they no longer do so because of additional, differential exposure to IGF-I due to dietary milk (Holmes et al. 2002) or other unknown influences. However, we measured IGF earlier in a woman's life than in our previous study (Hankinson et al. 1998).

Speculations about a secular trend in nutritional exposures, which may have led not only to growing obesity rates but also to an increase in insulin resistance, thereby possibly negating the impact of IGF-I, could not be corroborated in our analyses stratified on C-peptide levels as a marker for insulin resistance.

Another mechanistic interpretation (Pollak et al. 2004) of previous studies showing a higher breast cancer risk to be associated with higher IGF-I levels among premenopausal women was that higher IGF-I levels are associated with higher levels of IGF-I receptor activation in at-risk mammary epithelial cells. This was postulated to increase survival of cells with accumulating DNA damage, which would facilitate stepwise carcinogenesis and/or lead to a higher proliferation rate of early cancers, as suggested by experimental data $(\mathrm{Ng}$ et al. 1997). However, it is plausible that signaling at and downstream of the IGF-I receptor is a function not only of ligand levels, but also of polymorphic variation in genes encoding key signaling proteins. Thus, risk may vary in a complex fashion involving interactions between polymorphic variation of genes encoding signaling molecules and ligand levels. Ongoing studies will explore the possibility that the relationship between circulating IGF-I levels and risk is confined to subpopulations that can be genetically identified, and that discrepancies between population studies may relate, in part, to differences in genotype distribution.

Our study is prospective and of fairly large size, adding to the strength of our findings. With a large 
proportion of premenopausal women, we were able to address associations by menopausal status, with sufficiently large numbers of cases in each quartile. However, the youngest of our premenopausal women is more than 42 years old, which compromises the ability to assess risks among very young women even in this, to date one of the largest cohort studies among premenopausal women. Thus, larger cohorts of young women with a lower median age are needed to address whether IGF-I associations with breast cancer risk vary by age, and whether IGF levels in young women better reflect the exposure period of importance.

An advantage of our prospective design is that blood samples were collected before the occurrence of breast cancer, thus allowing us to evaluate circulating IGF-I levels as potential predictors for breast cancer rather than as tumor markers. However, with an average of only 31 months between blood collection and tumor diagnosis, the influence of a tumor that was not yet diagnosed cannot be completely ruled out, given the long latency period of breast cancer. We did exclude cases that occurred within the first year after blood collection, and breast cancer risks associated with IGF-I remained essentially unchanged; the modest increase of risk associated with IGFBP-3, however, suggests that studies with longer periods between blood collection and tumor diagnosis, particularly among premenopausal women, are needed to rule out a possible influence of a preclinical tumor on circulating IGF levels.

In summary, our study does not support findings from previous studies suggesting that the relation between IGF-I and breast cancer risk differs by menopausal status. While most but not all previous prospective studies reported a relatively strong, positive association between plasma IGF-I and breast cancer risk among premenopausal women, we could not corroborate these findings. Cohort effects may contribute complexity to these associations, which will need to be addressed in future cohort studies. Future studies will also need to further evaluate the usefulness of IGF-I as a prognostic marker for breast cancer.

\section{Acknowledgements}

This research was supported by National Cancer Institute (NCI) grants CA67262 and CA50385 and by the NCI Specialized Program of Research Excellence (SPORE) in breast cancer at the Channing Laboratory. Dr Pollak was partially supported by grants from the Streams of Excellence Program of the Canadian Breast Cancer Initiative. We are indebted to the participants of the ongoing Nurses' Health Study II for their continuing outstanding dedication to the study and to Karen Corsano for technical assistance. The authors declare that they have no financial interest in a company whose product was studied in the work presented in this paper.

\section{References}

Allen NE, Roddam AW, Allen DS, Fentiman IS, Dos Santos Silva I, Peto J, Holly JM \& Key TJ 2005 A prospective study of serum insulin-like growth factor-I (IGF-I), IGF-II, IGF-binding protein-3 and breast cancer risk. British Journal of Cancer 92 1283-1287.

Bates P, Fisher R, Ward A, Richardson L, Hill DJ \& Graham CF 1995 Mammary cancer in transgenic mice expressing insulin-like growth factor II (IGF-II). British Journal of Cancer 72 1189-1193.

Bland JM \& Altman DG 1986 Statistical methods for assessing agreement between two methods of clinical measurement. Lancet 1 307-310.

Bruning PF, Van Doorn J, Bonfrer JM, Van Noord PA, Korse CM, Linders TC \& Hart AA 1995 Insulin-like growth-factor-binding protein 3 is decreased in early stage operable pre-menopausal breast cancer. International Journal of Cancer 62 266-270.

Cheetham TD, Holly JM, Baxter RC, Meadows K, Jones J, Taylor AM \& Dunger DB 1998 The effects of recombinant human IGF-I administration on concentrations of acid labile subunit, IGF binding protein-3, IGF-I, IGF-II and proteolysis of IGF binding protein-3 in adolescents with insulin-dependent diabetes mellitus. Journal of Endocrinology 157 81-87.

Chellakooty M, Vangsgaard K, Larsen T, Scheike T, Falck-Larsen J, Legarth J, Andersson AM, Main KM, Skakkebaek NE \& Juul A 2004 A longitudinal study of intrauterine growth and the placental growth hormone (GH)-insulin-like growth factor I axis in maternal circulation: association between placental $\mathrm{GH}$ and fetal growth. Journal of Clinical Endocrinology and Metabolism 89 384-391.

Colditz GA \& Hankinson SE 2005 The Nurses' Health Study: lifestyle and health among women. Nature Reviews in Cancer 5 388-396.

Del Giudice ME, Fantus IG, Ezzat S, McKeown-Eyssen G, Page D \& Goodwin PJ 1998 Insulin and related factors in premenopausal breast cancer risk. Breast Cancer Research and Treatment 47 111-120.

Favoni RE, de Cupis A, Perrotta A, Sforzini S, Amoroso D, Pensa F \& Miglietta L 1995 Insulin-like growth factor-I (IGF-I) and IGF-binding proteins blood serum levels in women with early- and late-stage breast cancer: mutual relationship and possible correlations with patients' hormonal status. Journal of Cancer Research and Clinical Oncology $121674-682$. 
Giovannucci E, Pollak MN, Platz EA, Willett WC, Stampfer MJ, Majeed N, Colditz GA, Speizer FE \& Hankinson SE 2000 A prospective study of plasma insulin-like growth factor-I and binding protein-3 and risk of colorectal neoplasia in women. Cancer Epidemiology Biomarkers and Prevention 9 345-349.

Goodman-Gruen D \& Barrett-Connor E 1997 Epidemiology of insulin-like growth factor-I in elderly men and women. The Rancho Bernardo Study. American Journal of Epidemiology 145 970-976.

Goodwin PJ, Ennis M, Pritchard KI, Trudeau ME, Koo J, Hartwick W, Hoffman B \& Hood N 2002 Insulin-like growth factor binding proteins 1 and 3 and breast cancer outcomes. Breast Cancer Research and Treatment $\mathbf{7 4}$ 65-76.

Hankinson SE \& Schernhammer ES 2003 Insulin-like growth factor and breast cancer risk: evidence from observational studies. Breast Diseases 17 27-40.

Hankinson SE, Willett WC, Colditz GA, Hunter DJ, Michaud DS, Deroo B, Rosner B, Speizer FE \& Pollak M 1998 Circulating concentrations of insulin-like growth factor-I and risk of breast cancer. Lancet 351 1393-1396.

Helle SI, Anker GB, Meadows KA, Holly JM \& Lonning PE 1998 Alterations in the insulin-like growth factor system during the menstrual cycle in normal women. Maturitas $\mathbf{2 8}$ 259-265.

Holmes MD, Pollak M, Willett WC \& Hankinson SE 2002 Dietary correlates of plasma insulin-like growth factor I and insulin-like growth factor binding protein 3 concentrations. Cancer Epidemiology Biomarkers and Prevention 11 852-861.

Jones JI \& Clemmons DR 1995 Insulin-like growth factor binding proteins and their role in controlling IGF actions. Endocrine Reviews 16 3-34.

Juul A, Scheike T, Pedersen AT, Main KM, Andersson AM, Pedersen LM \& Skakkebaek NE 1997 Changes in serum concentrations of growth hormone, insulin, insulin-like growth factor and insulin-like growth factor-binding proteins 1 and 3 and urinary growth hormone excretion during the menstrual cycle. Human Reproduction 12 2123-2128.

Kaaks R, Lundin E, Rinaldi S, Manjer J, Biessy C, Soderberg S, Lenner P, Janzon L, Riboli E, Berglund G \& Hallmans G 2002 Prospective study of IGF-I, IGF-binding proteins, and breast cancer risk, in northern and southern Sweden. Cancer Causes Control 13 307-316.

Keinan-Boker L, Bueno de Mesquita HB, Kaaks R, van Gils $\mathrm{CH}$, Van Noord PAH, Rinaldi S, Riboli E, Seidell JC, Grobbee DE \& Peeters PHM 2002 Circulating levels of insulin-like growth factor I, its binding proteins 1-, -2, -3, C-peptide, and risk of postmenopausal breast cancer. International Journal of Cancer 106 90-95.

Krajcik RA, Borofsky ND, Massardo S \& Orentreich N 2002 Insulin-like growth factor (IGF-I), IGF-binding proteins, and breast cancer. Cancer Epidemiology Biomarkers and Prevention 11 1566-1573.
Medical Intelligence Unit 2003 Insulin-like growth factors. Eds. D Le Roith, W Zumkellar and R C Baxter. New York: Kluwer Academic.

Missmer SA, Bertone-Johnson ER, Spiegelman D, Barbieri RL, Pollak M \& Hankinson SE 2006 Reproducibility of plasma hormone and growth factor levels among premenopausal women over a 2-3 year period. Cancer Epidemiology Biomarkers and Prevention In Press.

Muti P, Quattrin T, Grant BJB, Krogh V, Micheli A, Schuenemann HJ, Ram M, Freudenheim JL, Sieri S, Trevisan M \& Berrino F 2002 Fasting glucose is a risk factor for breast cancer: a prospective study. Cancer Epidemiology Biomarkers and Prevention 11 1361-1368.

Ng ST, Zhou J, Adesanya OO, Wang J, LeRoith D \& Bondy CA 1997 Growth hormone treatment induces mammary gland hyperplasia in aging primates. Nature Medicine $\mathbf{3}$ 1141-1144.

Pollak MN, Schernhammer ES \& Hankinson SE 2004 Insulin-like growth factors and neoplasia. Nature Reviews in Cancer 47 505-518.

Rinaldi S, Kaaks R, Zeleniuch-Jacquotte A, Arslan AA, Shore RE, Koenig KL, Dossus L, Riboli E, Stattin P, Lukanova A \& Toniolo P 2005 Insulin-like growth factor-I, IGF binding protein-3, and breast cancer in young women: a comparison of risk estimates using different peptide assays. Cancer Epidemiology Biomarkers and Prevention 14 48-52.

Rockhill B, Willett WC, Hunter DJ, Manson JE, Hankinson SE, Spiegelman D \& Colditz GA 1998 Physical activity and breast cancer risk in a cohort of young women. Journal of the National Cancer Institute 90 1155-1160.

Rosner B 1983 Percentage points for a generalized ESD many-outlier procedure. Technometrics 25 165-172.

Schernhammer ES, Holly JM, Pollak MN \& Hankinson SE 2005 Circulating levels of insulin-like growth factors, their binding proteins, and breast cancer risk. Cancer Epidemiology Biomarkers and Prevention 14 699-704.

Shimasaki S \& Ling N 1991 Identification and molecular characterization of insulin-like growth factor binding proteins (IGFBP-1, -2, -3, -4, -5 and -6). Progress in Growth Factor Research 3 243-266.

Toniolo P, Bruning PF, Akhmedkhanov A, Bonfrer JM, Koenig KL, Lukanova A, Shore RE \& ZeleniuchJacquotte A 2000 Serum insulin-like growth factor-I and breast cancer. International Journal of Cancer $\mathbf{8 8} 828-832$.

Wei EK, Ma J, Pollak MN, Rifai N, Fuchs CS, Hankinson SE \& Giovannucci E 2005 A prospective study of C-peptide, insulin-like growth factor (IGF)-I, IGF binding protein 1, and the risk of colorectal cancer in women. Cancer Epidemiology Biomarkers and Prevention 14 850-855.

Yang XF, Beamer WG, Huynh H \& Pollak M 1996 Reduced growth of human breast cancer xenografts in hosts homozygous for the lit mutation. Cancer Research $\mathbf{5 6}$ 1509-1511.

Zeger SL, Liang KY \& Albert PS 1988 Models for longitudinal data: a generalized estimating equation approach. Biometrics 44 1049-1060. 